\title{
Rheological Properties of Cellular Structures Manufactured by Additive PJM Technology
}

\author{
Tomasz KOZIOR*, Czesław KUNDERA
}

\begin{abstract}
Intensive development of manufacturing technologies, in particular additive technologies, resulted in new possibilities of making cellular structure models. In this paper the cellular structure samples made of polymer resins in the PolyJet Matrix additive technology were investigated. Relaxation tests according to ISO 3384 were carried out. The influence of geometric structure shape on rheological properties was determined and the most favourable geometric variants of cellular structure models were determined. Using Mathematica and Origin software, a statistical analysis of test results was carried out, along with the determination of five-parameter functions approximating the relaxation curves. The rheological model was adopted and its parameters were determined.
\end{abstract}

Keywords: cell structures; PJM; rapid prototyping; rheological properties

\section{INTRODUCTION}

Due to their complex internal structure cellular structures are characterized by good strength properties, both static and dynamic. Moreover, cellular structures exhibit good energy absorption and mechanical vibration damping properties. With the development of technology, new opportunities have emerged for the use of cellular structures in many industries, such as mechanical engineering, aerospace, arms, filtering [18] but also in medicine. In addition, with the development of manufacturing, in particular additive technologies [1], new possibilities for the construction of cellular structure models have emerged. In the case of PolyJet technology (PJM) it is possible to produce objects from multiple materials simultaneously, which means that the models created have different physical and chemical properties in several places of the same model. This is particularly important in the case of manufacturing models responsible for vibration damping. Vibration dampers require both high damping properties and resistance to rheological phenomena occurring over time. Such models are subjected to continuous loads, which results in the phenomenon of stress relaxation. In addition, the PJM technology of photo-curing of liquid polymer resins allows the base materials to be mixed to create the optimum material for the specific solution. In many cases of cellular structures manufacturing, their interior is filled with liquid flexible material. However, this causes some technological difficulties. These problems can be solved by additive technologies such as PJM. With this method, there is no need to fill the inside of the structure with elastic material, as the material can be made of two materials, both soft and hard at once.

Mechanical properties (including chemical) and accuracy of models manufactured by additive technologies have been presented in numerous research works $[2-9,19]$. In the case of cellular structures manufactured by additive technology, there is a lack of sufficient information on their rheological properties. Selected properties of cellular structures manufactured by additive technology have been described in several research papers [10-12].

In the paper [10], the authors examined samples manufactured by conventional and unconventional methods. The initial structure of the sample models was fabricated with the use of PolyJet additive technology and FullCure M840 material, which was then filled with liquid silicone by casting. The samples were then subjected to static and dynamic compression tests. Basic mechanical properties for different types of tests and geometric variants of structure models were determined.

In the paper [11] measurements of cellular structures of models fabricated with the use of $3 \mathrm{D}$ printer implementing selective electron-beam melting technology and titanium powder Ti-6Al-4 V were carried out. In the course of the tests, both actual measurements of the manufactured structure models were carried out with the use of a hydraulic testing machine and strength simulations of selected geometries. Moreover, the mass and porosity of cellular structure models as well as stress-strain curves for variable load parameters were determined and compared with the results of computer simulations. The results showed a very high influence of porosity of cellular structures, geometric shape of structures, loading direction and parameters on mechanical properties and energy absorption parameters.

In the paper [12], models of cellular structures made of 7075 aluminium alloy with the addition of zinc were tested. The authors carried out fatigue tests using a universal testing machine. The tests results were compared with the results obtained through computer simulations. In addition, an analysis of the microstructure of samples after rupture was carried out using a scanning electron microscope. The influence of surface roughness parameters on fatigue strength of aluminium samples was taken into account in the tests.

Using the results of own preliminary research and basing on the literature review, we can state that cellular structures manufactured by additive technologies have plenty of advantages that determine their real use in various industrial applications. Therefore, in this research paper the authors present the results of relaxation measurements of different models of cellular structures made of three types of photopolymer resins in PJM technology. Based on experimental relaxation curves a relative decrease in compressive stresses was determined and parameters of the rheological model used to describe viscoelastic properties of the examined cellular structure models were identified.

\section{MATERIALS AND METHODS}

The Connex 350 from Stratasys was used to build the sample models. This machine allows for the production of polymer sample models using the PolyJet Matrix (PJM) technology of photo-curing of liquid polymer resins (Fig. 
1). In this technology, liquid polymer resins are jetted at the place of the currently built layer corresponding to the cross section of the model, and then using lamps, which are the source of ultraviolet light, the polymerization process is initiated, resulting in the layer being cured and joined with the previously formed layer.

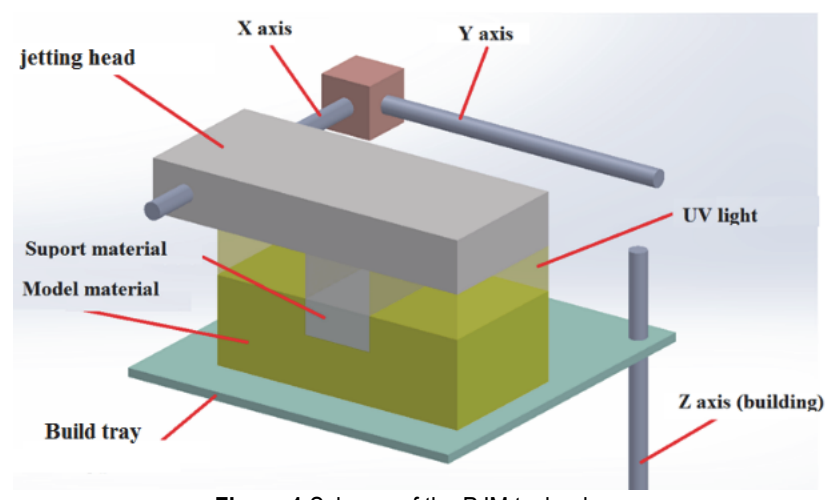

Figure 1 Scheme of the PJM technology

All sample models were designed using Solidworks software and then saved as "stl" files in a so-called customized saving mode. Parameters for saving the "stl" files were as follows: deviation tolerance of 0.01 , angle tolerance of $5^{\circ}$. The "stl" files have been subjected to an approximation check using the Materialise Magics 15.0 software. The analysis of the model did not reveal any errors. Then the models were placed on a virtual build tray and fabricated with the predetermined technological parameters, i.e. the thickness of the layer being built of $0.032 \mathrm{~mm}$.

The sample models of cellular structure were made of three photopolymer resins: two hard resins, FullCure 720 (FC 720) and VeroWhite (VW), and a soft support material, FullCure 705 (FC 705). Chemical compositions and selected mechanical properties given by the manufacturer of the material, i.e. Stratasys, are presented in Tabs. 1 to 4 below [13].

Tables 1 Chemical composition of VeroWhite

\begin{tabular}{|c|c|c|}
\hline \multicolumn{2}{|c}{ Tables 1 Chemical composition of VeroWhite } \\
\hline Not Available & Components & Percentage \\
\hline Proprietary & Monomer & $30-50$ \\
\hline $5888-33-5$ & $\begin{array}{c}\text { 2-propenoic acid, 1, 7, 7- } \\
\text { trimethylbicyclo[2.2.1]hept- } \\
\text { 2-yl ester, exo- }\end{array}$ & $10-30$ \\
\hline $87320-05-6$ & $\begin{array}{c}{[2-[1,1-\text { dimethyll-2[(1- }} \\
\text { oxoallyl)oxy]-5-ethyl-1, 3- } \\
\text { dioxan-5yl]methyl acrylate }\end{array}$ & $0-10$ \\
\hline 154508-99-8 & Epoxy acrylic oligomer & $1-10$ \\
\hline Proprietary & Photoinitiator & $1-5$ \\
\hline
\end{tabular}

Tables 2 Chemical composition of FullCure 720

\begin{tabular}{|c|c|c|}
\multicolumn{2}{|c}{ Tables 2 Chemical composition of FullCure 720 } \\
\hline CAS & Components & Percentage \\
\hline--- & Acrylic monomer & $<30$ \\
\hline $588-33-5$ & Isobornyl acrylate & $<25$ \\
\hline--- & $\begin{array}{c}\text { Phenol, 4, 4'-(1-methylethylidene)bis- } \\
\text { polymer with (chloromethyl)oxirane, 2- } \\
\text { propenoate }\end{array}$ & $<15$ \\
\hline--- & $\begin{array}{c}\text { Phosphine oxide, phenylbis(2, 4, 6- } \\
\text { trimethylbenzoyl)- }\end{array}$ & $<2$ \\
\hline $52408-84-1$ & Acrylic acid ester & $<0.3$ \\
\hline
\end{tabular}

Samples for testing were fabricated in six geometric variants (Fig. 2). The shape and dimensions of the samples were selected to match the stress relaxation test samples in accordance with ISO [14] standard.

Tables 3 Chemical composition of FullCure 705 - support material

\begin{tabular}{|c|c|c|}
\hline CAS & Components & Percentage \\
\hline-- & $\begin{array}{c}\text { Poly(oxy-1,2-ethanediyl), } \alpha-(1- \\
\text { oxo-2-propenyl)- } \omega \text {-hydroxy- }\end{array}$ & $<50$ \\
\hline $57-55-6$ & 1, 2-Propylene glycol & $<35$ \\
\hline $25322-68-3$ & Polyethylene glycerol & $<30$ \\
\hline $56-81-5$ & Glycerin & $<25$ \\
\hline-- & $\begin{array}{c}\text { Phosphine oxide, phenylbis(2, 4, } \\
\text { 6-trimethylbenzoyl)- }\end{array}$ & $<0.5$ \\
\hline $52408-84-1$ & Acrylic acid ester & $<0.3$ \\
\hline
\end{tabular}

Tables 4 Properties of materials

\begin{tabular}{|c|c|c|c|c|c|}
\hline Material & $\begin{array}{c}\text { Young } \\
\text { modulus }\end{array}$ & $\begin{array}{c}\text { Tensile } \\
\text { Strength }\end{array}$ & Impact & Hardness & Density \\
\hline FullCure 720 & 2870 & 60 & 24 & 83 & $1.18-1.19$ \\
\hline VeroWhite & 2500 & 50 & 24 & 83 & $1.18-1.19$ \\
\hline Unit & $\mathrm{MPa}$ & $\mathrm{MPa}$ & $\mathrm{J} / \mathrm{cm}^{2}$ & Shore'a D & $\mathrm{g} / \mathrm{cm}^{3}$ \\
\hline Standard & $\begin{array}{c}\text { EN ISO } \\
527\end{array}$ & $\begin{array}{c}\text { ISO } \\
180 / 1 \mathrm{~A}\end{array}$ & $\begin{array}{c}\text { ISO } \\
868\end{array}$ & EOS & - \\
\hline
\end{tabular}

All test samples had the following external dimensions: diameter $13 \mathrm{~mm}$, height $6.3 \mathrm{~mm}$. Samples marked with letters A and B (Fig. 2) were made of base materials, i.e. FC 720 and VW resin. The sample marked with the letter $\mathrm{C}$ is made of two base materials in the form of two joined discs, both $3.15 \mathrm{~mm}$ high. Sample D, like sample C, was made of FC 720 and VW material, and in addition two cylindrical channels $2 \mathrm{~mm}$ in diameter perpendicular to the axis were made in each half, which were filled alternately with base materials. The shape and dimensions of sample E are identical to sample D with the difference that the inner cylindrical channels were filled with FC 705. The sample marked with the letter F is made of two interconnected discs, each $3.15 \mathrm{~mm}$ high (FC and VW) and two $4 \mathrm{~mm}$ diameter channels filled with FC705 material. The last variants of samples $\mathrm{G}, \mathrm{H}$ are similar to samples E, F, with the difference that the holes are not filled.
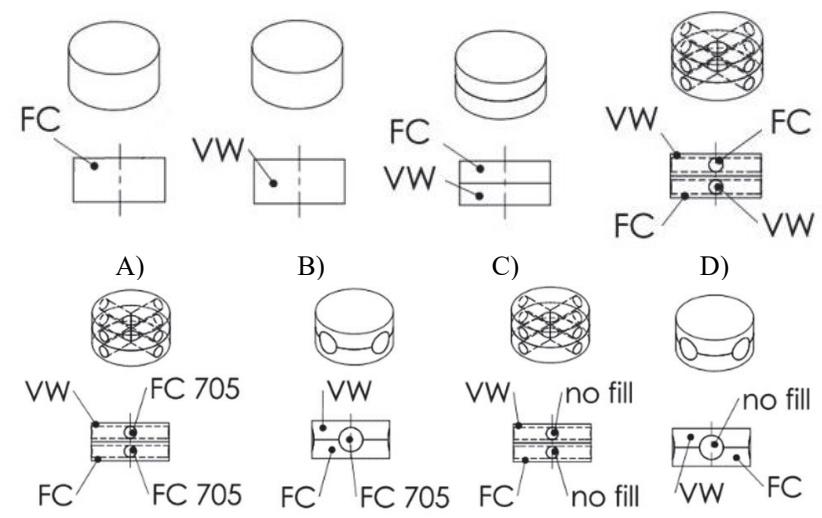

B)

C)

D)
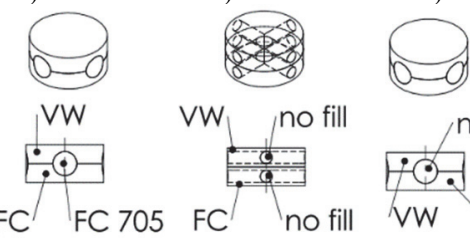

no fill<smiles>[C]1[CH]C=C1</smiles>
VW FC

E)

F)

G)

H)

Fig. 3 shows examples of fabricated samples after cleaning the support material.

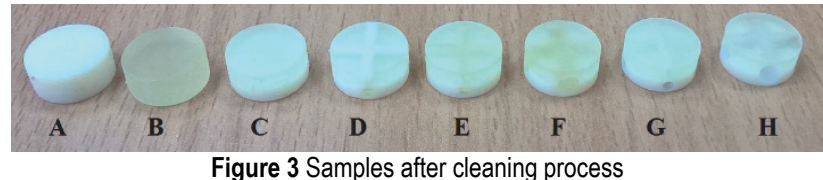

Figure 3 Samples after cleaning process 
The sample models placed on the tray were divided into 256 layers and had a building time of 34 minutes. After printing and cleaning, the samples were subjected to relaxation tests. The stress relaxation tests were performed using a Hegewald\&PeschkeInspekt Mini universal testing machine. The samples were compressed at a speed of 1 $\mathrm{mm} / \mathrm{s}$, with a deformation value of $10 \%$ of the sample height, i.e. $0.63 \mathrm{~mm}$. Then, for a period of 60 minutes, a decrease in stress as a function of time was recorded. After completion of the measurements according to ISO 3384, the relative decrease in compressive stress relaxation was calculated according to the following relation:

$\Delta \sigma=\frac{\sigma_{0}-\sigma_{t}}{\sigma_{0}}$

where: $\sigma_{0}$ - initial stress; $\sigma_{t}$ - stress after the predetermined relaxation time $t$.
In further description of the relaxation measurement results, the relative decrease in compressive stress (1) will be called the stress relaxation indicator.

\section{RESEARCH RESULTS AND DISCUSSION 3.1 Stress Relaxation}

Results of the calculation of compressive stresses relaxation indicators for each test sample of a given structure (Fig. 3) are presented in Tab. 5.

Tab. 5 shows, for each type of sample, three values of stress relaxation indicator $x_{i 1}, x_{i 2}, x_{i 3}$, the average value of relaxation indicator $\Delta \sigma$ marked with the symbol $\bar{x}$, in addition, the symbol $S$ denotes the standard deviation, the symbol Up the measurement uncertainty calculated for $95 \%$ significance level, as well as the confidence interval of the results obtained.

Tables $\mathbf{5}$ Summary of results of statistical analysis

\begin{tabular}{|c|c|c|c|c|c|c|c|c|}
\hline Sample & $\bar{x}_{i 1}$ & $\bar{x}_{i 2}$ & $\bar{x}_{i 3}$ & $\bar{x}_{i}$ & $S$ & $U_{p}$ & \multicolumn{2}{|c|}{$\bar{x}_{i} \pm U_{p}$} \\
\hline $\mathrm{A}$ & 0.068 & 0.042 & 0.067 & 0.059 & 0.015 & 0.064 & -0.005 & 0.123 \\
\hline $\mathrm{B}$ & 0.038 & 0.040 & 0.043 & 0.041 & 0,003 & 0.011 & 0.03 & 0.052 \\
\hline $\mathrm{C}$ & 0.05 & 0.055 & 0.073 & 0.059 & 0.012 & 0.052 & 0.007 & 0.111 \\
\hline $\mathrm{D}$ & 0.037 & 0.037 & 0.056 & 0.043 & 0.011 & 0.045 & -0.004 & 0.09 \\
\hline $\mathrm{E}$ & 0.048 & 0.062 & 0.052 & 0.054 & 0.007 & 0.031 & 0.023 & 0.085 \\
\hline $\mathrm{F}$ & 0.080 & 0.121 & 0.107 & 0.103 & 0.021 & 0.089 & 0.014 & 0.192 \\
\hline $\mathrm{G}$ & 0.08 & 0.072 & 0.062 & 0.071 & 0.009 & 0.038 & 0.033 & 0.110 \\
\hline $\mathrm{H}$ & 0.111 & 0.185 & 0.186 & 0.161 & 0.043 & 0.186 & -0.025 & 0.347 \\
\hline
\end{tabular}

The following figures (Fig. 4) present experimental characteristics of relaxation of compressive stresses for the tested samples marked with letters $(\mathrm{A}-\mathrm{H})$ as in Fig. 3.

Based on the obtained results of measurements of relative decrease in compressive stress (Tab. 6), it can be stated that there are significant differences in the values of this indicator for the examined types of cellular structures. For base materials (FullCure 720 and VeroWhite), the highest mean relaxation indicator was determined for FullCure 720 sample models, $\bar{x}-0.059$ (sample A). In addition, the introduction of additional modifications in the form of channels filled with FC 705 model material increases the stress relaxation indicator while maintaining the minimum stress relaxation values for FullCure 720 ( $\bar{x}$ $-0.059)$ and VeroWhite $720(\bar{x}-0.041)$. The introduction of soft material in sample models $E$ and $F$ results in an increase in relaxation indicator to 0.054 and 0.103 , respectively, which corresponds to higher stress decreases. It should be noted that the combination of soft and hard materials in one model might result in a decrease in stress relaxation while maintaining very good energy absorption properties, which will be the subject of further dynamic testing of the models presented.

\subsection{Identification of the Parameters of the Rheological Model}

More or less complex rheological models can be used to describe mathematically the rheological properties of viscoelastic materials [15-17]. The parameters of these models are always determined experimentally.

Basing on the results obtained from the measurement (tests) of relaxation of compressive stresses, their approximation using a five-parameter relaxation function in the form below was performed:

$\sigma(t)=\sigma_{0}+\sigma_{1} \mathrm{e}^{-\frac{t}{t_{1}}}+\sigma_{2} \mathrm{e}^{-\frac{t}{t_{2}}}$

where: $\sigma_{0}, \sigma_{1}, \sigma_{2}$ - partial stresses; $t_{1}, t_{2}$ - relaxation times.

Fitting the relaxation function (2) to the particular results obtained in the experiment was performed by means of the Origin program. In this program, the LevenbergMarquardt method (L-M) is used to approximate experimental data with an exponential function. In addition, the accuracy of approximation (matching) is calculated (estimated) on the basis of compatibility factors $\chi^{2}$ and determination coefficients $R^{2}$.

The adopted stress relaxation function (2) is a response to the predetermined step displacement in the relaxation test $\sigma(t)=\varepsilon_{0} H(t)$ for the material (body) described by the Maxwell-Wiechert rheological model (M-W), a diagram of which is shown in Fig. 5.

The relaxation function (2), taking into account the parameters of the rheological model, can also be written in the following form:

$\sigma(t)=\varepsilon_{0}\left(E_{0}+E_{1} \mathrm{e}^{-\frac{t}{t_{1}}}+E_{2} \mathrm{e}^{-\frac{t}{t_{2}}}\right)$

where: $\varepsilon_{0}$ - predetermined relative displacement in the relaxation test $\varepsilon(t)=\varepsilon_{0} H(t) ; H(t)$ - Heaviside function; $t_{1}$, $t_{2}$ - relaxation times; $t_{1}=\eta_{1} / E_{1} ; t_{2}=\eta_{2} / E_{2} ; E_{0}, E_{1}, E_{2}, \eta_{1}$, $\eta_{2}$ - the parameters of the rheological model. 


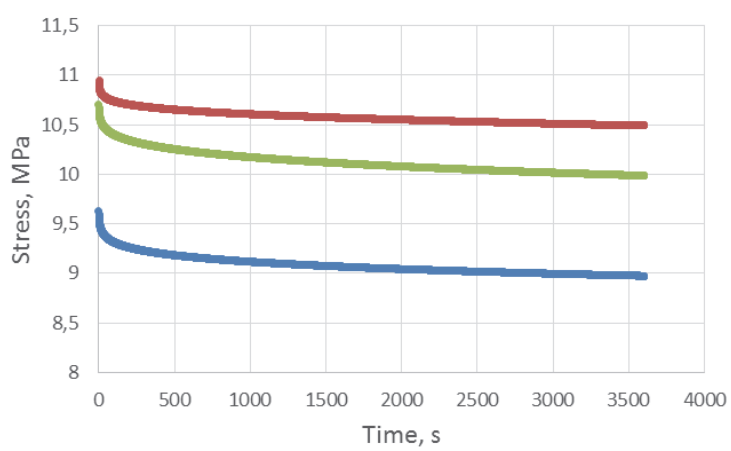

a)

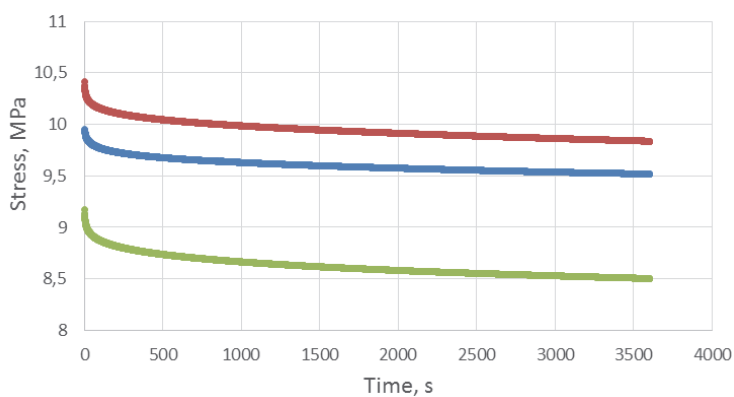

c)

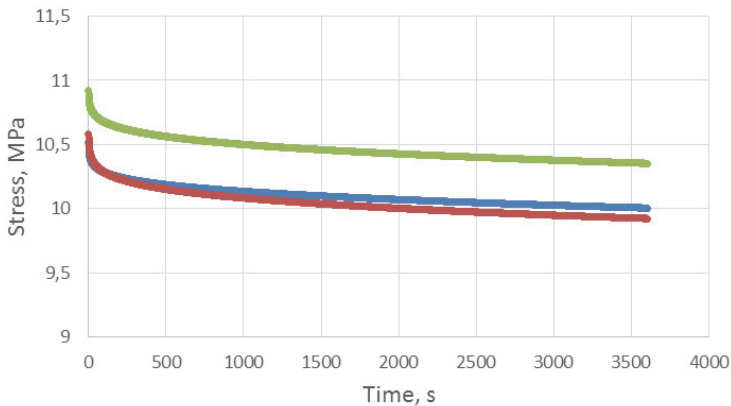

e)

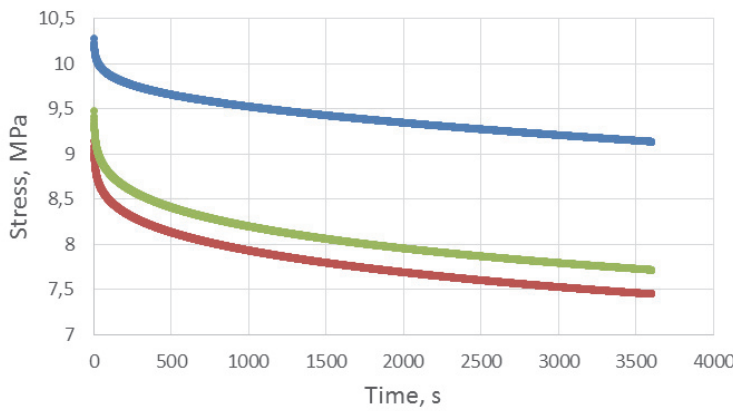

g)

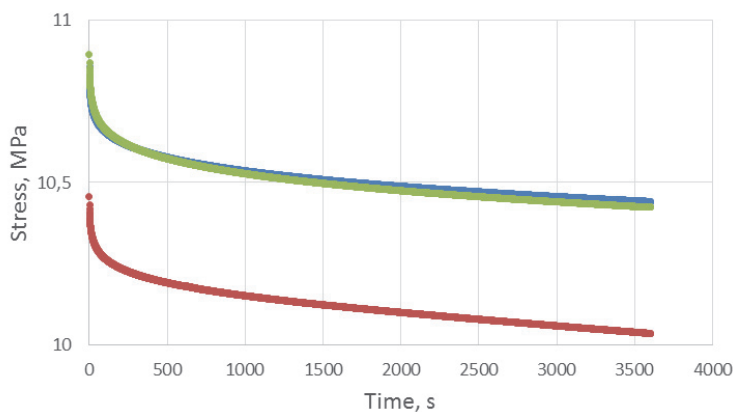

b)

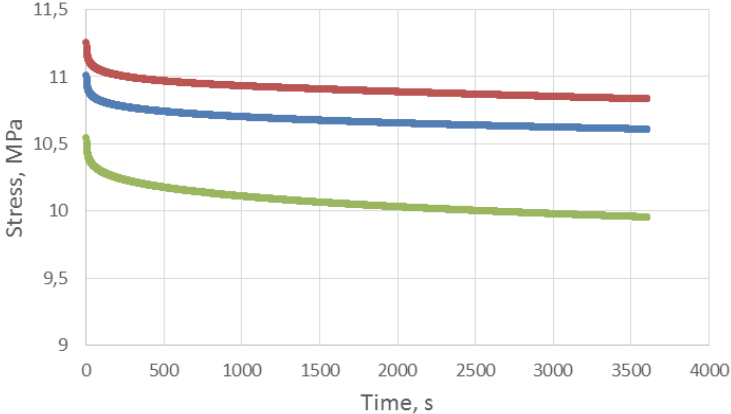

d)

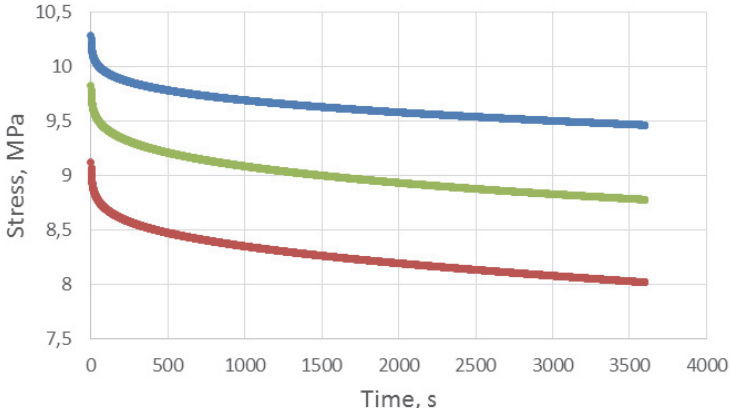

f)

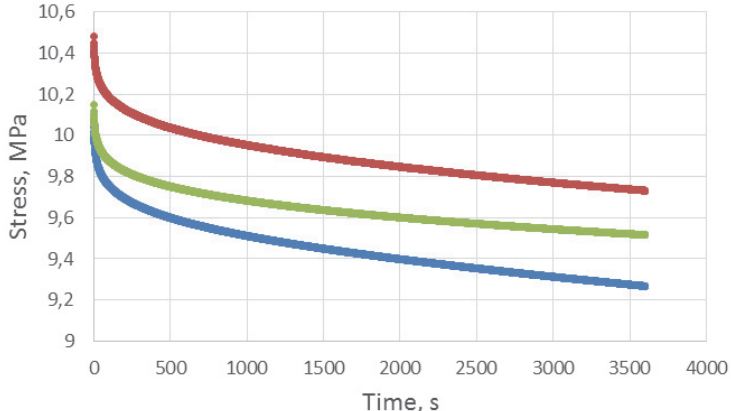

h)

Figure 4 Relaxation characteristics of test samples A-H

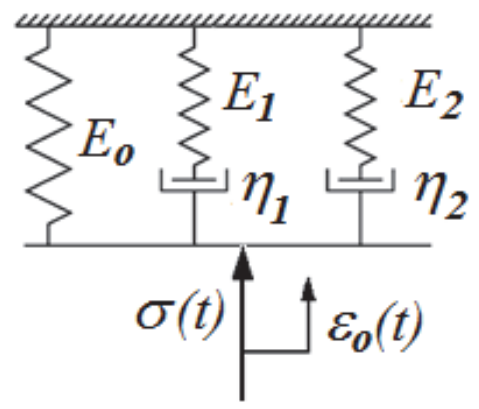

Figure 5 Rheological model

Examples of approximation of experimental relaxation characteristics with values of function parameters (2) and matching accuracy factors are shown in Figs. 6 and 7.

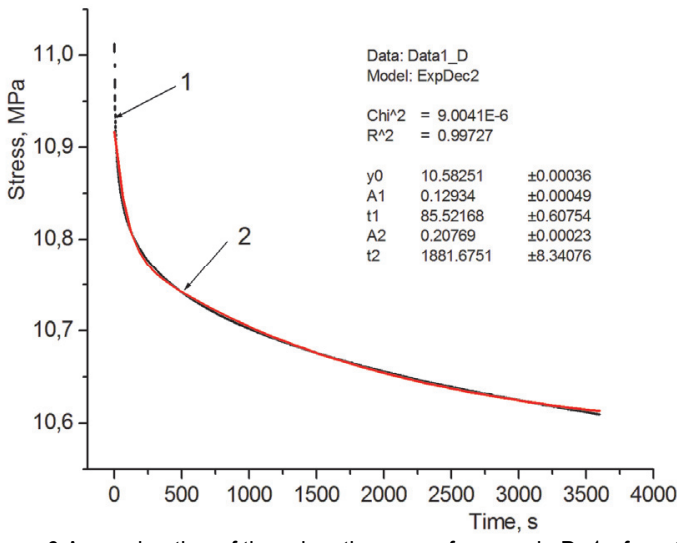

Figure 6 Approximation of the relaxation curve for sample D: 1 - from the experiment; 2 - relaxation function 


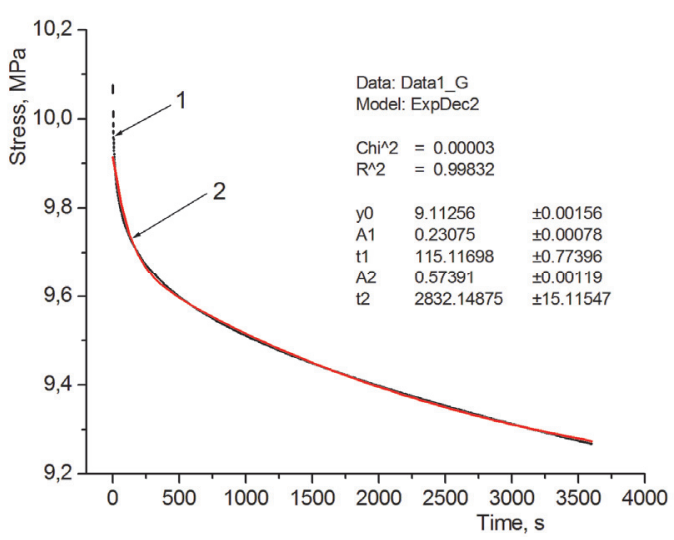

Figure 7 Approximation of the relaxation curve for sample G: 1 - from the experiment; 2 - relaxation function
The examples of functions approximating experimental relaxation curves and the calculated compatibility $\chi^{2}$ and determination $R^{2}$ coefficients, shown in Figs. 6 and 7, show that they are very well matched (approximated).

Basing on the obtained parameters of relaxation curves approximation functions it is easy to calculate the parameters of $\mathrm{M}-\mathrm{W}$ rheological model (Fig. 5). Tab. 7 shows the values of these parameters, i.e. modulus of elasticity and modulus of viscosity for individual test samples (Fig. 2). Additionally, the values of the equivalent modulus of elasticity $\left(E_{\mathrm{s}}=E_{0}+E_{1}+E_{2}\right)$ and stress relaxation indicator $\Delta \sigma$ were written.

Tables 6 Parameters of the rheological model

\begin{tabular}{|c|c|c|c|c|c|c|c|}
\hline Sample & $E_{0} / \mathrm{MPa}$ & $E_{1} / \mathrm{MPa}$ & $E_{2} / \mathrm{MPa}$ & $\eta_{1} / \mathrm{MPa} \cdot \mathrm{s}$ & $\eta_{2} / \mathrm{MPa} \cdot \mathrm{s}$ & $E_{\mathrm{s}} / \mathrm{MPa}$ & $\Delta \sigma / \%$ \\
\hline$A$ & 99.206 & 2.189 & 4.206 & 239.182 & 8457.558 & 105.601 & 5.9 \\
\hline$B$ & 104.149 & 1.307 & 2.124 & 118.530 & 3907.668 & 107.581 & 4.1 \\
\hline$C$ & 94.801 & 1.634 & 2.516 & 146.092 & 4969.956 & 98.952 & 5.9 \\
\hline$D$ & 105.825 & 1.293 & 2.077 & 110.614 & 3908.051 & 109.195 & 4.3 \\
\hline$E$ & 98.696 & 2.081 & 3.607 & 210.607 & 7054.132 & 104.384 & 5.4 \\
\hline$F$ & 86.520 & 2.994 & 6.916 & 344.479 & 15116.94 & 96.431 & 10.3 \\
\hline$G$ & 91.126 & 2.307 & 5.739 & 265.632 & 16253.98 & 99.172 & 7.1 \\
\hline$H$ & 75.573 & 5.218 & 10.835 & 604.167 & 21325.51 & 91.626 & 16.1 \\
\hline
\end{tabular}

Based on relaxation tests and parameters of the M-W rheological model obtained because of approximation, it can be stated that cellular structures made of polymeric materials using the PJM additive method show significant differences in viscoelastic properties. Comparison of the values of equivalent modulus of elasticity $\left(E_{\mathrm{s}}\right)$ and relaxation indicator $(\Delta \sigma)$ shows that samples with lower elasticity have higher compressive stress drops. Sandwichtype samples $(\mathrm{D} \div \mathrm{H}$ ), made of base materials (FC 720, VW) with similar mechanical properties, are characterized by different elastic properties ( $E_{\mathrm{s}}$ modulus) and damping properties (modulus $\eta_{1}, \eta_{2}$ ), after making internal modifications in their structure. Sandwich-type samples with internal channels filled with soft material (FC 705 resin) exhibit higher values of modulus of elasticity $E_{\mathrm{s}}$ compared to identical samples with unfilled channels.

The five-parameter $\mathrm{M}-\mathrm{W}$ model used to describe relaxation is well characterized by viscoelastic properties of photopolymeric materials used in PJM technology, as well as cellular structures made of them (made of these materials).

\section{CONCLUSIONS}

On the basis of the results of experimental research and analyses, the following general conclusions can be drawn:

The results of stress relaxation measurements determined during the single-axis compression test indicate that models made of VeroWhite material are characterized by the highest rheological strength, i.e. the lowest relaxation, whilst those made of FullCure 720 material - by the highest relaxation. Moreover, intermediate results were obtained for combinations of the above mentioned materials in various geometric configurations.

The use of FullCure 705 as a support material for the cellular structure allows us to state that it is suitable for the production of objects with low resistance to continuous load, but also to conclude that this material may exhibit high energy absorption properties.

The five-parameter Maxwell-Wiechert rheological model can be used with high accuracy for the description of rheological properties of polymeric materials and cell structures made of these materials. It also expands the possibilities of modelling cellular structures for the assumed relaxation properties, and more precisely for the assumed parameters of the rheological model describing given structure.

\section{REFERENCES}

[1] Campbell, I., Bourell, D., \& Gibson, I. (2012). Additive manufacturing: rapid prototyping comes of age. Rapid Prototyping Journal, 18, 255-258. https://doi.org/10.1108/13552541211231563

[2] Budzik, G., Burek, J., Bazan, A., \& Turek, P. (2016). Analysis of the Accuracy of Reconstructed Two Teeth Models Manufactured Using the 3DP and FDM Technologies. Strojniški vestnik - Journal of Mechanical Engineering, 62, 11-20. https://doi.org/10.5545/sv-jme.2015.2699

[3] Kozior, T., Döpke, C., Grimmelsmann, N., Junger, I. J., \& Ehrmann, A. (2018). Influence of fabric pretreatment on adhesion of three-dimensional printed material on textile substrates. Advances in Mechanical Engineering, 10, 1-8. https://doi.org/10.1177/1687814018792316

[4] Adamczak, S., Zmarzły, P., Kozior, T., \& Gogolewski G. (2018). Analysis of the dimensional accuracy of casting models manufactured by fused deposition modeling technology. 23rd International Conference ENGINEERING MECHANICS 2017, 66-69.

[5] Wagner, A., Kreuzer, A. M., Göpperl, L., Schranzhofera, L., \& Paulik, C. (2019). Foamable acrylic based ink for the production of light weight parts by inkjet-based 3D printing. European Polymer, 115, 325-334.

https://doi.org/10.1016/j.eurpolymj.2019.03.031 
[6] Pérez-Tamarit, S., Solórzano, E., Hilger, A., Manke, I., \& Rodríguez-Pérez, M. A. (2018). Multi-scale tomographic analysis of polymeric foams: A detailed study of the cellular structure. European Polymer. Journal 109, 169-178. https://doi.org/10.1016/j.eurpolymj.2018.09.047

[7] Dizon, J. R. C., Espera, A. H. Jr., Chen, Q., \& Advincula, R. C. (2018). Mechanical characterization of 3D-printed polymers. Additive Manufacturing Journal, 20, 44-67. https://doi.org/10.1016/j.addma.2017.12.002

[8] Kundera, C. \& Kozior, T. (2017). Evaluation of the influence of parameters of FDM technology on the selected mechanical properties of models. Procedia Engineering, 192, 463-468. https://doi.org/10.1016/j.proeng.2017.06.080

[9] Blok, L. G., Longana, M. L., Yu, H., \& Woods, B. K. S (2018). An investigation into 3D printing of fibre reinforced thermoplastic composites. Additive Manufacturing Journal, 22, 176-186. https://doi.org/10.1016/j.addma.2018.04.039

[10] Vesenjak, M., Krstulović-Opara, L., \& Ren Z. (2012). Characterization of photopolymer cellular structure with silicone pore filler. Polymer Testing, 31, 705-709. https://doi.org/10.1016/j.polymertesting.2012.04.007

[11] Novak, N., Vesenjak, M., Krstulović-Opara, L., \& Ren, Z. (2018). Mechanical characterisation of auxetic cellular structures built from inverted tetrapods. Composite Structures, 196, 96-107. https://doi.org/10.1016/j.compstruct.2018.05.024

[12] Tomažinčič, D., Nečemer, B., Vesenjak, M., \& Klemenc, J. (2019). Low-cycle fatigue life of thin-plate auxetic cellular structures made from aluminium alloy 7075-T651. Fatigue \& Fracture of Engineering Materials \& Structure, 1-15. https://doi.org/10.1111/ffe.12966

[13] Materials sheet data. Retrieved from: https://www.stratasys.com/materials/search

[14] ISO 3384-1:2011: Rubber, vulcanized or thermoplastic Determination of stress relaxation in compression - Part 1: Testing at constant temperature.

[15] Bochnia, J. \& Blasiak, S. (2019). Fractional relaxation model of materials obtained with selective laser sintering technology. Rapid Prototyping Journal, 25, 76-86. https://doi.org/10.1108/RPJ-11-2017-0236

[16] Kundera, C. \& Bochnia, J. (2014). Investigating the stress relaxation of photopolymer O-ring seal models Rapid Prototyping Journal, 20, 533-540. https://doi.org/10.1108/RPJ-04-2013-0043

[17] Brinson, H. F. \& Brinson, L. C. (2015). Polymer engineering science and viscoelasticity. New York, Springer.

[18] Kozior, T., Mamun, A., Trabelsi, M., Sabantina, L., \& Ehrmann, A. (2019). Stabilization of Electrospun Nanofiber Mats Used for Filters by 3D Printing. Polymers, 11, 1-11. https://doi.org/10.3390/polym11101618

[19] Kundera, C., Martsynkowskyy, V., Gudkov, S., \& Kozior, T. (2017). Effect of rheological parameters of elastomeric ring materials on dynamic of face seals. Procedia Engineering, 177, 307-313. https://doi.org/10.1016/j.proeng.2017.02.230

\section{Contact information:}

Tomasz KOZIOR, PhD

(Corresponding author)

Kielce University of Technology,

Al. 1000-lecia P. P. 7, 25-314 Kielce, Poland

E-mail: tkozior@tu.kielce.pl

Czesław KUNDERA, Full Professor

Kielce University of Technology,

Al. 1000-lecia P. P. 7, 25-314 Kielce, Poland

E-mail: kundera@tu.kielce.pl 